\title{
Artikel
}

\section{Tenietgaan van zekerheidsrechten door contractsoverneming}

\author{
Mr. M. Huizingh*
}

\section{Inleiding}

Contractsoverneming komt veel voor. Contracten worden bijvoorbeeld overgenomen in het kader van bedrijfsovernames, bij samenwerking tussen bedrijven of in verband met herstructurering. Bij overneming blijft het contract, de rechtsverhouding, ongewijzigd in stand en wijzigt in beginsel alleen de partij daarbij. Dit betekent evenwel niet dat contractsoverneming niets meer dan een partijwijziging tot gevolg kan hebben. Wat in de praktijk weinig bekendheid geniet, is dat contractsoverneming tot het tenietgaan van zekerheidsrechten kan leiden. Bij het aangaan of begeleiden van een contractsoverneming is van belang te weten of de zekerheidsrechten, die in verband met het over te nemen contract bestaan, al dan niet in stand zullen blijven na de overneming

In dit artikel wordt beschreven in welke gevallen contractsoverneming leidt tot het tenietgaan van zekerheidsrechten, waarbij eerst de rechten van pand en hypotheek aan de orde komen en daarna de rechten uit borgtocht. Vervolgens komt aan de orde wat kan worden gedaan om te voorkomen dat zekerheden tenietgaan en in hoeverre een onbedoeld tenietgaan nog kan worden teruggedraaid.

Dat bepaalde zekerheidsrechten kunnen vervallen door contractsoverneming is een risico als partijen daar niet op bedacht zijn, maar biedt in sommige gevallen ook juist kansen. Aan het slot van dit artikel wordt beschre-

Mr. M. Huizingh is advocaat te Enschede en als fellow verbonden aan het Onderzoekscentrum Onderneming en Recht van de Radboud Universiteit Nijmegen. ven hoe kan worden geprofiteerd van het vervallen van zekerheidsrechten door contractsoverneming.

\section{Overgang van vorderingen en schulden}

Bij contractsoverneming gaan alle vorderingen en schulden uit het contract over van de overdrager op de overnemer. Zekerheidsrechten die zijn gevestigd tot zekerheid voor de vordering die door contractsoverneming overgaat, blijven bij contractsoverneming in stand. Dergelijke zekerheden gaan als nevenrechten mee over op de overnemer (art. 6:142 Burgerlijk Wetboek (BW)). Heeft een leverancier bijvoorbeeld een pandrecht op de voorraden van zijn afnemer tot zekerheid voor het leverancierskrediet, en draagt hij de leverantieovereenkomst over aan een nieuwe leverancier (bijvoorbeeld bij verkoop van zijn onderneming), dan gaat de vordering op de afnemer over op de nieuwe leverancier en komt het pandrecht de nieuwe leverancier na de overneming als nevenrecht toe. De nieuwe leverancier kan het pandrecht zo nodig ten laste van de afnemer uitwinnen.

Als ditzelfde contract niet aan de kant van de leverancier wordt overgedragen, maar aan de kant van de afnemer, gaat niet een vordering op de afnemer over, maar een schuld van de afnemer. De nieuwe afnemer is de nieuwe schuldenaar. Het pandrecht strekt tot zekerheid voor de vordering van de leverancier op de afnemer. Vanuit de afnemer bezien strekt het pandrecht tot zekerheid voor de schuld die hij heeft aan de leverancier. Je kunt hier dus spreken van de overgang van de schuld tot zekerheid waarvoor een pandrecht is gevestigd. Voor die situatie geldt een andere regeling. In de wet is bepaald dat de rechten van pand en hypotheek die strekken tot 
zekerheid van een overgegane schuld blijven bestaan, mits zij zijn gevestigd op een goed dat aan een van de partijen toebehoort.

De rechten uit borgtocht en de rechten van pand en hypotheek gevestigd op een goed van een derde, gaan echter teniet, tenzij de borg c.q. de pand- of hypotheekgever in de handhaving van het zekerheidsrecht heeft toegestemd (art. 6:157 lid 2 jo. art. 6:159 lid 3 BW). In het gegeven voorbeeld, waarbij een leverantieovereenkomst wordt overgenomen door een nieuwe afnemer en de leverancier een pandrecht heeft op de voorraden van zijn afnemer tot zekerheid voor het leverancierskrediet, is deze regeling van toepassing. Verleent de leverancier medewerking aan een dergelijke contractsoverneming, dan blijft het pandrecht op de voorraden van de oorspronkelijke afnemer bestaan. Het pandrecht is immers gevestigd op goederen van de oorspronkelijke afnemer en die is partij bij de contractsoverneming. Schiet de nieuwe afnemer tekort jegens de leverancier, dan kan de leverancier het pandrecht op de voorraden van de oude afnemer uitwinnen.

Hierna wordt eerst voor pand en hypotheek en daarna voor borgtocht uitgewerkt wanneer deze zekerheidsrechten tenietgaan, en vervolgens wat je kunt doen om dat te voorkomen of juist te benutten.

\section{Pand en hypotheek}

Als gezegd is in artikel 6:157 lid 2 BW bepaald dat de rechten van pand en hypotheek, tot zekerheid voor de nakoming van een schuld gevestigd op een goed dat niet aan een van de partijen toebehoort, tenietgaan bij overgang van de schuld, tenzij de pand- of hypotheekhouder tevoren in de handhaving van het zekerheidsrecht heeft toegestemd. Dit geldt, blijkens de schakelbepaling van artikel 6:159 lid $3 \mathrm{BW}$, ook wanneer de schuld overgaat door contractsoverneming.

Het pand- of hypotheekrecht vervalt dus wanneer het (a) gevestigd is op een goed van een derde en (b) deze derde niet van tevoren heeft toegestemd in de handhaving van het recht ná de overneming.

Bij contractsoverneming is sprake van een derdenpand of derdenhypotheek als het pand- of hypotheekrecht gevestigd is op een goed dat niet toebehoort aan een van de partijen bij de contractsoverneming. Het moet dus gaan om een zekerheidsrecht op een goed dat niet van de overdrager, de overnemer of de wederpartij is. Een derdenzekerheid kan op een aantal manieren ontstaan. In de eerste plaats doordat een derde zekerheid verstrekt ten behoeve van de schuldenaar. Dit gebeurt bijvoorbeeld wanneer ouders een hypotheekrecht vestigen op hun huis om het mogelijk te maken dat hun kind een lening verkrijgt waarvoor het kind zelf niet voldoende zekerheid kan verstrekken. Een ander voorbeeld is de directeur-grootaandeelhouder die, ter verkriiging van een zakelijk krediet, een hypotheekrecht vestigt op zijn woning. In de tweede plaats ontstaat een derdenzekerheid als de schuld, waarvoor de schuldenaar een pand- of hypotheekrecht heeft gevestigd op een aan hem toebehorend goed, overgaat op een ander, bijvoorbeeld door contractsoverneming. Het pand- of hypotheekrecht bliift dan (ingevolge art. 6:157 lid $2 \mathrm{BW}$ ) bestaan en strekt vanaf de overgang van de schuld tot zekerheid voor de nakoming daarvan door de overnemer, de nieuwe schuldenaar. Verder ontstaat een derdenzekerheid wanneer de eigendom van het verpande of verhypothekeerde goed overgaat op een derde, met in stand blijven van het pand- of hypotheekrecht. ${ }^{1}$

In elk van deze gevallen moet de pand- of hypotheekgever vooraf toestemmen in de handhaving van het zekerheidsrecht. $^{2}$

De achtergrond van de wettelijke regeling over het vervallen van derdenzekerheid bij overgang van de schuld is dat het zekerheidsrecht, als het zonder meer zou blijven bestaan, gaat dienen tot zekerheid voor de schuld van een nieuwe schuldenaar die mogelijk minder verhaal biedt dan de oude schuldenaar, zonder dat de derdezekerheidsgever hierbij betrokken is of zich hiertegen kan verzetten. ${ }^{3}$ De derdezekerheidsgever wordt geacht zekerheid te hebben verstrekt met het oog op de persoon van de schuldenaar. Het zekerheidsrecht is niet bedoeld om, zonder toestemming van de zekerheidsgever, tot zekerheid te strekken voor de schuld van een ander dan de oorspronkelijke schuldenaar. ${ }^{4}$ Daarom moet de derdezekerheidsgever erin toestemmen dat het zekerheidsrecht, na de overgang van de schuld op een nieuwe schuldenaar, in stand blijft. Is deze toestemming er niet, dan vervalt het derdenpand- of het derdenhypotheekrecht.

Gaat een schuld over door schuldoverneming dan moet de toestemming worden gegeven vóór de overgang van de schuld. ${ }^{5}$ Bij contractsoverneming geldt dat de toestemming moet worden gegeven vóór de overgang van de rechtsverhouding. Het moment van overgang is bij contractsoverneming het moment waarop voldaan is aan het aktevereiste en het vereiste van medewerking door de wederpartij. ${ }^{6}$ Is medewerking bij voorbaat verleend,

1. Vgl. T.J. Mellema-Kranenburg, Verbintenissenrecht (losbl.), art. 6:155 BW, aant. 3; J.W.A. Biemans, Het faillissement van de derde-rechthebbende, Tijdschrift voor Insolventierecht 2009/nr. 2.1.

2. Is sprake van opeenvolgende contractsovernemingen waarbij het zekerheidsrecht in eerste instantie gevestigd was op een goed van de oorspronkelijke schuldenaar (de overdrager bij de eerste contractsoverneming), dan blijft het zekerheidsrecht bij de eerste overneming zonder meer bestaan, maar blijft het bij de tweede overneming alleen bestaan wanneer de eigenaar van het goed (de oorspronkelijke schuldenaar en overdrager bij de eerste contractsoverneming) tijdig in de handhaving van het zekerheidsrecht toestemt.

3. Zie Parl. Gesch. Boek 6, p. 585 e.v.

4. Vgl. S.G. Canes, Schuldoverneming (diss. UvA), Hilversum: De Blaeuwe Werelt 1903, p. 180-181; C. Van Loggerenberg, Skuldoorname en Kontraksoorname, 'n Regsvergelykende ondersoek met besondere verwysing na die Suid-Afrikaanse reg (diss. Leiden), Leiden/Pijnacker: Dutch Efficiency Bureau 1981, p. 158-161; J.J. Verhoeven, Schuldoverneming: een vergelijking van de schuldoverneming met de passieve schuldvernieuwing (diss. Groningen), 2002, p. 280-282.

5. Zie Parl. Gesch. Boek 6, p. 581; J.J. Verhoeven, Schuldoverneming: een vergelijking van de schuldoverneming met de passieve schuldvernieuwing (diss. Groningen) 2002, p. 282.

6. Zie Asser/Sieburgh 6-II, Deventer: Wolters Kluwer 2017, nr. 308; T.J. Mellema-Kranenburg, Verbintenissenrecht (losbl.), art. 6:159 BW, aant. 
dan vindt overgang van de rechtsverhouding plaats op het moment dat de akte is opgemaakt en er mededeling is gedaan van de overneming aan de wederpartij. De toestemming van de derdenpand- of hypotheekgever moet dus worden verkregen voordat de wederpartij medewerking verleent aan de contractsoverneming of voordat hem van de overneming mededeling wordt gedaan.

\section{Borgtocht}

Voor rechten uit borgtocht geldt hetzelfde als voor pand- en hypotheekrechten op een goed van een derde. De rechten uit borgtocht gaan teniet, tenzij de borg tevoren met de handhaving daarvan instemt. De achterliggende gedachte hiervan is dat de persoon van de schuldenaar voor de borg van belang is. De borg stelt zich garant voor de schuld van een bepaalde hem bekende schuldenaar, mogelijk om redenen die verband houden met de relatie tussen hem en de schuldenaar of wegens met de schuldenaar gemaakte afspraken die de borg zekerheid bieden van regres in het geval de borgtocht wordt uitgewonnen. ${ }^{7}$ De borg kan niet tegen zijn wil worden gedwongen borg te staan voor een andere schuldenaar. Met de regeling van artikel 6:157 lid 2 BW wordt voorkomen dat de borg zonder het te weten en eventueel tegen zijn wil borg wordt voor de schuld van een ander dan de oorspronkelijke schuldenaar.

In de handhaving van de borgtocht moet, net als in de handhaving van het derdenpand- of derdenhypotheekrecht, vóór de contractsoverneming worden toegestemd.

\section{Tenietgaan van zekerheden voorkomen}

De zekerheidsgerechtigde zal doorgaans zijn zekerheden willen behouden, ook na de contractsoverneming. Iedere wederpartij die het verzoek krijgt medewerking te verlenen aan een contractsoverneming doet hij er goed aan eerst in kaart te brengen of de vorderingen die voor hem uit de overeenkomst voortvloeien zijn versterkt door rechten van pand of hypotheek op goederen van derden of door borgtocht. Als dat het geval is zal de zekerheidsgever er vóór de contractsoverneming uitdrukkelijk (bij voorkeur schriftelijk) in moeten toestemmen dat het zekerheidsrecht ook na de contractsoverneming in stand blijft. Het verlenen van medewerking aan contractsover-

4.3; M. Huizingh, Contractsoverneming (diss. Nijmegen), Deventer: Kluwer 2016, nr. 136.

7. Vgl. S.G. Canes, Schuldoverneming (diss. UvA), Hilversum: De Blaeuwe Werelt 1903, p. 178-180, C. Van Loggerenberg, Skuldoorname en Kontraksoorname, 'n Regsvergelykende ondersoek met besondere verwysing na die Suid-Afrikaanse reg (diss. Leiden), Leiden, Pijnacker: Dutch Efficiency Bureau 1981, p. 150-157; J.J. Verhoeven, Schuldoverneming: een vergelijking van de schuldoverneming met de passieve schuldvernieuwing (diss. Groningen) 2002, p. 280-282 neming is vormvrij en kan dus ook besloten liggen in gedragingen, waardoor het moment waarop de contractsoverneming tot stand komt niet altijd duidelijk is. ${ }^{8}$ Omdat de toestemming van de zekerheidsgerechtigde in de handhaving van het zekerheidsrecht vóór de contractsoverneming moet zijn gegeven, is van belang dat de medewerking aan de contractsoverneming niet ongemerkt plaatsvindt. Doet een partij mededeling van een (voorgenomen) contractsoverneming die mogelijkerwijs tot het tenietgaan van zekerheidsrechten leidt, dan is het voor de wederpartij raadzaam om ondubbelzinnig kenbaar te maken dat geen medewerking aan de contractsoverneming wordt verleend, tenzij alle in verband met het contract bestaande zekerheidsrechten ook na de contractsoverneming in stand zullen blijven. Na de bevestiging van de zekerheidsgever dat in de handhaving van de zekerheidsrechten wordt toegestemd (of na het verkrijgen van vervangende zekerheid) kan alsnog aan de contractsoverneming worden meegewerkt.

\section{Toestemming achteraf}

Als de borg of de derdenpand- of hypotheekgever niet voor de contractsoverneming toestemming verleent voor de handhaving van het zekerheidsrecht gaat het zekerheidsrecht teniet. Dit tenietgaan kan niet worden hersteld door toestemming achteraf. Als partijen na de rechtsgeldige totstandkoming van de contractsoverneming ontdekken dat er niet tijdig is toegestemd in de handhaving van het zekerheidsrecht, terwijl de borg of de derdenpand- of hypotheekgever - als hij van de voorgenomen contractsoverneming had geweten - daaraan zijn toestemming zou hebben verleend en hij ook achteraf bereid is alsnog zijn toestemming te verlenen, is het zekerheidsrecht niettemin tenietgegaan. Voor de borgtocht zal dit in de meeste gevallen niet tot een onoverkomelijk nadeel leiden. Wanneer de borg na de contractsoverneming verklaart dat hij desverzocht in de handhaving daarvan zou hebben toegestemd, is aannemelijk dat hij bereid zal zijn zich ook voor de nieuwe schuldenaar (de overnemer) borg te stellen en kan een nieuwe borgtochtovereenkomst worden gesloten ten gunste van de nieuwe schuldenaar. Voor de rechten van pand en hypotheek ligt dit minder eenvoudig.

Uit de parlementaire geschiedenis blijkt dat toestemming achteraf niet tot gevolg heeft dat het pand- of hypotheekrecht herleeft of geacht moet worden te zijn blijven bestaan. ${ }^{9}$ Het zou volgens de wetgever in strijd zijn met de rechtszekerheid indien het pand- of hypotheekrecht zou herleven nadat het door de overgang van de schuld eerst teniet is gegaan..$^{10}$ In sommige gevallen zal de toestemming van de pand- of hypotheekgever

8. Zie M. Huizingh, Contractsoverneming (diss. Nijmegen), Deventer, Kluwer 2016, nr. 136, met verwijzing naar relevante rechtspraak.

9. Vgl. M.P. van Achterberg, Overgang van vorderingen en schulden en afstand van vorderingen (Monografieën Nieuw BW nr. B44), Deventer: Kluwer 1999, nr. 56.

10. Parl. Gesch. Boek 6, p. 581. 
allicht geacht kunnen worden stilzwijgend te zijn verleend voor de overneming. Voorwaarde om stilzwijgende toestemming te kunnen aannemen is dat de zekerheidsgever op de hoogte was van de (voorgenomen) contractsoverneming. Iemand kan immers geen toestemming verlenen (uitdrukkelijk noch stilzwijgend) voor het handhaven van een recht bij een overneming waarvan hij geen weet heeft. Is de toestemming niet op tijd verleend (niet uitdrukkelijk en niet stilzwijgend), dan is het derdenpand- of hypotheekrecht vervallen. Dit kan alleen worden 'hersteld' door een nieuw pand- of hypotheekrecht te vestigen. Nadeel daarvan is dat opnieuw vestigingshandelingen moeten worden verricht (als het gaat om een hypotheekrecht moeten partijen opnieuw naar de notaris), maar belangrijker nog is dat zich hierdoor onbedoeld rangwijzigingen kunnen voordoen. Neem als voorbeeld de situatie dat onderneming A (een bv) een schuld heeft aan een leverancier uit een leverantieovereenkomst. Een van de aandeelhouders van de onderneming (niet tevens de bestuurder) heeft een eerste recht van hypotheek gevestigd op zijn woning ten gunste van de leverancier, tot zekerheid voor de nakoming van de schuld van de onderneming. Op de woning van de aandeelhouder is nadien een tweede recht van hypotheek gevestigd ten gunste van $\mathrm{X}$, een schuldeiser van de aandeelhouder. Op enig moment richt onderneming A dochteronderneming $\mathrm{B}$ op, die de activa en passiva van de onderneming overneemt. Onderdeel van de overname is de leverantieovereenkomst. De leverancier werkt mee aan de contractsoverneming door dochteronderneming B. Stel nu dat de partijen bij deze contractsoverneming de aandeelhouder (de derdenhypotheekgever) niet vóór de contractsoverneming vragen toe te stemmen in de handhaving van het hypotheekrecht. Aangenomen dat de aandeelhouder niet vooraf in kennis is gesteld van de contractsoverneming en derhalve ook niet geacht kan worden stilzwijgend te hebben toegestemd in de handhaving daarvan, vervalt het eerste recht van hypotheek van de leverancier. Partijen kunnen, zodra zij dit ontdekken, slechts nog een nieuw recht van hypotheek vestigen. Dat hypotheekrecht zal dan rang nemen ná het hypotheekrecht van $\mathrm{X}$, die hierdoor onbedoeld wordt bevoordeeld ten nadele van de leverancier. De vervalregeling van artikel 6:157 lid 2 BW heeft ten doel te voorkomen dat de derdezekerheidsgever wordt benadeeld door de overgang van de schuld tot zekerheid waarvoor hij zich als pand- of hypotheekgever sterk heeft gemaakt. Gaat het zekerheidsrecht evenwel teniet terwijl de zekerheidsgever dit niet beoogde en ook niet wilde, dan schiet de bescherming van artikel 6:157 lid 2 BW haar doel voorbij. ${ }^{11}$ Een remedie hiertegen, een

11. Zie ook C. Van Loggerenberg, Skuldoorname en Kontraksoorname, 'n Regsvergelykende ondersoek met besondere verwysing na die Suid-Afrikaanse reg (diss. Leiden), Leiden, Pijnacker: Dutch Efficiency Bureau 1981, p. 158-161, die de regeling van verval van derdenzekerheden van rechtswege bij het ontbreken van toestemming in de handhaving daarvan, zoals thans opgenomen in art. 6:157 lid 2 BW, bekritiseert en pleit voor een systeem waarbij de derdezekerheidsgever slechts wordt beschermd tegen daadwerkelijke benadeling als gevolg van overgang van de schuld. manier om de door partijen niet gewenste gevolgen van het tenietgaan van het zekerheidsrecht ongedaan te maken, lijkt de wet niet te bieden. Zo biedt bijvoorbeeld bekrachtiging (art. 3:58 BW) in dit geval geen soelaas. Door bekrachtiging kan onder bepaalde omstandigheden een nietige rechtshandeling alsnog (met terugwerkende kracht) geldig worden. In het hier besproken geval is evenwel geen sprake van een nietige rechtshandeling die door bekrachtiging geldig kan worden, maar van een geldige rechtshandeling die (door het ontbreken van voorafgaande toestemming) mede het tenietgaan van een zekerheidsrecht tot gevolg heeft. Een dergelijk rechtsgevolg kan niet door bekrachtiging ongedaan worden gemaakt.

De bescherming die met de regeling van artikel 6:157 lid $2 \mathrm{BW}$ is beoogd, had ook geboden kunnen worden door aan de derdezekerheidsgever de bevoegdheid toe te kennen het pand- of hypotheekrecht te laten vervallen door middel van een daartoe tot de schuldeiser gerichte verklaring indien hij niet voor de overneming heeft toegestemd in de handhaving van het hypotheekrecht.

\section{De vervalregeling biedt ook kansen}

Voor de zekerheidsgerechtigde heeft de vervalregeling van artikel 6:157 lid 2 BW de hiervoor beschreven nadelen. Voor de zekerheidsgever kan de regeling juist kansen bieden. Hoe vaak gebeurt het niet dat een directeurgrootaandeelhouder zich sterk maakt voor zijn onderneming (als borg, pand- of hypotheekgever) en op enig moment onder de als knellend ervaren zekerheid uit wil? In de praktijk wordt dan (bij borgtocht) veelal als eerste onderzocht of er een echtgenoot is die op de voet van artikel 1:88 BW toestemming had moeten geven voor de borgstelling. Heeft de directeur-grootaandeelhouder een pandrecht verstrekt, dan biedt dit artikel geen uitkomst en bij vestiging van een hypotheekrecht zal doorgaans door de notaris zijn toegezien op het verkrijgen van de eventueel vereiste toestemming. Baat artikel 1:88 BW niet, dan kan het de moeite lonen om te onderzoeken of de borgtocht op enig moment op grond van artikel 6:157 lid $2 \mathrm{BW}$ teniet is gegaan doordat de schuld is overgegaan op een derde zonder dat de borg in de handhaving daarvan heeft toegestemd. Dat kan in het kader van een overname (activa/passiva) zijn gebeurd of bij een herstructurering (inbreng in een opgerichte vennootschap). Is bij de overname aan de borgtocht geen aandacht besteed (hetgeen in de praktijk dikwijls voorkomt; overnamedocumentatie is soms uiterst summier), dan zal de borg de toestemming en daarmee het bestaan van de borgtocht ter discussie kunnen stellen. ${ }^{12}$

12. Gaat het om borgstelling door een directeur-grootaandeelhouder ten behoeve van zijn onderneming en heeft de directeur betrokkenheid gehad bij de overname of inbreng waarbij de door borgtocht verzekerde schuld is overgegaan, dan is niet uitgesloten dat de directeur/borg 
Een pand- of hypotheekgever kan alleen een beroep doen op artikel 6:157 lid 2 BW als sprake is van een derdenpand of derdenhypotheek. Dit speelt (als gezegd) in drie gevallen: wanneer het pand- of hypotheekrecht direct is gevestigd op het goed van een ander dan de schuldenaar, als door overgang van de schuld een ander dan de eigenaar van het bezwaarde goed schuldenaar is geworden, of als door overgang van het goed een ander dan de schuldenaar eigenaar is geworden van het bezwaarde goed. Als de overeenkomst waaruit een door een derdenpand of derdenhypotheek verzekerde schuld voortvloeit, twee keer met medewerking van de schuldeiser is overgenomen en de oorspronkelijke schuldenaar bij de tweede overneming niet tijdig in de handhaving van het pand- of hypotheekrecht heeft toegestemd, is het zekerheidsrecht vervallen. Twee opeenvolgende contractsovernemingen kunnen dus meebrengen dat het zekerheidsrecht vervalt.

\section{Samenvatting en conclusie}

Uitgangspunt is dat de zekerheden verbonden an een overeenkomst bij overneming mee overgaan. Gaat het echter om derdenzekerheden verbonden aan de schuld die door de contractsoverneming overgaat, dan moet de zekerheidsgever vooraf toestemmen in de handhaving daarvan. Gebeurt dat niet, dan vervalt de zekerheid, ook als partijen dat niet beoogden. Toestemming achteraf doet het zekerheidsrecht niet 'herleven'. Is het verval van rechten uit borgtocht niet gewenst, dan kunnen deze rechten doorgaans zonder bezwaar opnieuw worden aangegaan. Maar zijn rechten van pand of hypotheek eenmaal vervallen, dan moeten zij opnieuw worden gevestigd, met als nadeel dat opnieuw aan de vestigingsformaliteiten moet worden voldaan en dat er een onbedoeld rangwisseling kan plaatsvinden. Wederpartijen die het verzoek krijgen medewerking te verlenen aan de overneming van een contract, zouden die medewerking voor de zekerheid moeten verlenen onder de voorwaarde dat alle (eventuele) zekerheidsrechten in stand blijven. Voor partijen die zich willen bevrijden van de last van in het verleden verstrekte zekerheidsrechten, kan de regeling van artikel 6:157 lid $2 \mathrm{BW}$ eventueel soelaas bieden, bijvoorbeeld bij twee opeenvolgende contractsovernemingen.

Conclusie is dat contractsoverneming het onverwachte gevolg kan hebben dat bepaalde zekerheidsrechten tenietgaan. Partijen die zich daar niet van bewust zijn lopen het risico dat hun verhaalspositie ongemerkt en ongewild verslechtert. Wie de wettelijke regeling over het tenietgaan van zekerheidsrechten bij overgang van schulden daarentegen goed kent en toepast, kan daar in bepaalde gevallen zijn voordeel mee doen. 